Competing Interests:

None declared.

Ethical approval:

Not applicable.

Author's contribution: $B B^{1}$ and $N N^{2}$ prepared

the manuscript in entirety.

Funding:

None declared.

Acknowledgements:

None declared.

\title{
Building the Future of EU: Moving Forward with International Collaboration on Blockchain
}

Bill Buchanan ${ }^{1}$, OBE, PhD; Naseem Naqvi ${ }^{2}$ FRCP MAcadMed

${ }^{1}$ Professor of Computing, The Cyber Academy, Edinburgh Napier University, UK

${ }^{2}$ Co-founder, The British Blockchain Association, UK

Correspondence: B.Buchanan@napier.ac.uk

Received: 15 April 2018 Accepted: 25 April 2018 Published: 27 April 2018

\begin{abstract}
A blockchain enabled 'Digital Single Economy" can act as a catalyst for growth and could provide a platform where borderless innovative practices will thrive and create a true collaborative global economy, with shared goals and objectives for the benefit of wider community. A society where digital economy flourishes irrespective of geopolitical ideologies and where a technology like Blockchain holds transformative potential to unite the nations together. The UK currently has strong collaborations around blockchain including with the British Blockchain Association which aims to integrate with the EU on the adoption of Blockchain based methods around a range of application areas. However, at the core of these alliances must be the promotion of technology which link industry, the public sector, and academia, whilst also integrating key stakeholders, such as law enforcement, finance, health care, professional bodies and the legal industry.
\end{abstract}

Keywords: digital, blockechain, economy, British, European, collaboration

\section{An old world}

The Internet we have now differs little from the one that was created in the 1980s. Basically we are often using the methods developed around TCP and IP, with security integrated to fill-in the gaps around security. Few things on the Internet, though, can be trusted, and where every email we receive cannot be properly verified for its sender, and whether someone else has either viewed or edited the email. Our IT infrastructure is thus often frozen in the 20th Century, with very little usage of integrated security especially in defining ownership and for access control. For identity checking we have grown accustomed to usernames and password, and where our passwords are stored in a hashed format. We end up, too, having multiple identities across multiple platforms, and often have very little control of our own data.

The IT systems have created have been basically mirrored on a form filling work, and where we repeatedly enter the same information across multiple systems. For a world which aims to move to a citizencentric approach, and where data is controlled by its owner, we are a long way off, and will probably never get there without a radical change in our approach. This change will be to build the Internet has it was meant to be, and where trust is integrated into every part of the infrastructure. Our failure is generally around the concept of a third-party trust model, and where Bob and Alice rely on Trent to identify themselves to each other. But what if Bob and Alice do not trust anyone?

Our new world will embed identity, rights and citizenship at its core, and be built around Bob and Alice transacting, and only requiring Trent when they think it is best for them. This world will properly define identity and enact smart contracts which do not need a third party to be involved.

\section{Rebuilding a new world}

To build this new world requires international collaboration, and it is a world which might not respect international borders, laws and rights. Without collaboration we cannot build an infrastructure that can scale from the local level (micro) to a world-wide level (macro). It will require new models of operation, and where laws are rewritten to be enacted as smart contracts. Isn't it a strange world that we see a scrawl of a pen across a page as a more creditable proof of our identity than our private key or our biometrics? This, though, will change, but requires the collaboration of technologists, academics, politicians, and law makers. 
Blockchain is thus seen by Gartner as one of the ten technologies in the next decade will are likely to be one of the most disruptive [1].

The US has moved greatly on integrating cryptography and smart contracts into the statute on several states. At part of this the federal Electronic Signatures in Global and National Commerce Act (ESIGN Act) [2] and the Uniform Electronic Transactions Act (UETA) [3] aim to support the legal basis for the integration of legal contracts. Using these Acts as a foundation, on 3 April 2018, Arizona has defined that organisation can now hold and share data on a blockchain. These amendments build on laws which recognise digital signatures and smart contracts as legal entities.

The EU, though, has not moved as fast on supporting the usage of digital signatures and smart contracts, but it has moved on the rights of the citizen. With GDPR to be enacted in May 2018, the requirement to rebuild the Internet has never been so relevant.

\section{International collaboration}

The Internet is no respecter of national borders, and new eco-systems are being built which often have little respect for the laws and regulations within national borders. International collaboration thus must be at the heart of most economies, especially in emerging areas of technology. Without it nations can often struggle to catch-up with others when they are excluded from research projects. Along with this politicians and law makers could end-up suppressing innovation within their countries.

In order to advanced Blockchain collaboration, 22 EU countries have now signed up to a collaboration document, with a focus on creating a Digital Single Economy. List of countries among the signatories of the Declaration are: Austria, Belgium, Bulgaria, Czech Republic, Estonia, Finland, France, Germany, Ireland, Latvia, Lithuania, Luxembourg, Malta, Netherlands, Norway, Poland, Portugal, Slovakia, Slovenia, Spain, Sweden, UK.

This collaboration will allow the nations to exchange knowledge and thus prepare for the roll-out of systems based on blockchain methods. This will include private sector areas around finance and energy, along with public sector applications within government systems and health care. In order to show that the UK aims to continue to collaborate within digital applications it has eagerly signed up to both the implementation of GDPR and to the Digital Single Economy.

The Commission for Digital Economy and Society Mariya Gabriel - showcases the transformation that Blockchain, smart contracts and digital signing are likely to bring [4], by saying:
"In the future, all public services will use blockechain technology. Blockchain is a great opportunity for Europe and Member States to rethink their information systems, to promote user trust and the protection of personal data, to help create new business opportunities and to establish new areas of leadership, benefiting citizens, public services and companies. The Partnership launched today enables Member States to work together with the European Commission to turn the enormous potential of blockchain technology into better services for citizens".

With the collaboration around blockchain, the 22 nations will be able to more closely share data, and define new models for governance, consent and rights. To support this the European Commission has also created the EU Blockchain Observatory and Forum and has invested over $€ 80$ million in blockchain and has set aside more than $€ 300$ million in investment by 2020 .

\section{Conclusion}

Trust is at the heart of EU economy and in incorporating the transition to a digital single market. The Blockchain can streamline public \& government interactions and provide frictionless opportunities for consumers and businesses. All too often, these opportunities get stifled by onerous regulations due to lack of standardized benchmarks. It is time we put this right by building foundations on a blockchain based ecosystem which can unlock an enormous, untapped, growth potential. We believe that blockchain, if harnessed appropriately, can be a source for significant productivity and would nurture tangible benefits for the post Brexit United Kingdom. We need to work together constructively and make decisions based on best available evidence to ensure that we reap the full potential of Blockchain and other Distributed Ledger Technologies.

\section{References}

[1] D. W. Cearley, B. Burke, and M. J. Walker, "Top 10 strategic technology trends for 2018," Gartner Research, 2017. [Online]. Available: https://mmm.gartner.com/ document $/ 3811368$ ? ref = TrackDBDTextEmailes refv $a l=1507125606933$. [Accessed: 15-Apr-2018].

[2] "Summary: Bills Pertaining to Digital Signatures and Authentication in the 106th Congress." [Online]. Available: http:/ / wmw.techlawjournal.com/ cong106/digsig/Default.htm. [Accessed: 15-Apr-2018].

[3] J. P. Mazurek, D. Benjamin, and C. R. Beattie, "UNIFORM ELECTRONIC TRANSACTIONS ACT (1999).”

\section{[4] "European countries join Blockechain Partnership | Digital Single Market." [Online]. Available: https://ec.europa. eu/digital-single-market/ en / news/ european-countries-join- blockechain-partnership. [Accessed: 15-Apr-2018]}

